\title{
Editorial
}

\section{Do Not Let Your CEO Even Read This!}

\author{
Martin Brink
}

This Editorial is about corporate mediation, and that is not always CEO stuff. The question is raised whether your CEO is open to this corporate mediation stuff.

The role of a CEO is important. He or she has to decide, orchestrate and oversee the execution of a vast number of important issues. That constantly requires the fullest of attention: designing and aligning the strategy; dealing with stakeholders, such as shareholders, supervisors or important customers; promoting the mission statement of the organisation; protecting the bottom line; hiring key personnel; acting as arbitrator in conflicts; and sensing whether a major change in direction is needed, to mention but a few items on the list.

The reputation of an organisation can supposedly be attributed for $45 \%$ - almost half in total - to its CEO. Of 1,700 senior managers in 19 countries worldwide, who were interviewed by PR Agency Weber Shandwick in $2015,81 \%$ considered the involvement and visibility of the CEO to be of crucial importance for the reputation of an organisation. They also believed that the reputation of the CEO was relevant for the results of the organisation (to an extent of 44\% of the market value). This normally means, both in small and large organisations, that much attention of a successful CEO will go to building a strong presence within the branch of industry, so a lot of focus will be on creating a connection between the organisation and the outer world.

Equally important is the connection of the CEO with the inner world of the organisation. There has to be a balanced equilibrium between image and identity of the organisation. This avoids that customers, shareholders or potential employees who were attracted by the image of an organisation become disappointed once they decide to form a relationship with that organisation or opt for its products or services. Any discrepancy nowadays may soon be met with negative exposure that can travel around the globe in an instant. In April 2017, United Continental Holdings, the parent company of
United Airlines, announced that the airline CEO, Oscar Munoz, will not take broader control of the company as previously planned, following an incident that damaged the company's reputation. It had taken him three turns to publically say 'sorry' for an incident whereby Dr. David Dao, a booked passenger who had paid for his ticket, was with force removed from one of United's airplanes. Dao had refused to give up his seat for commuting crew members. Amateur images of the incident made the news worldwide. The company's first response, attributed to $\mathrm{Munoz}$, did not go over well. $\mathrm{He}$ issued a statement that apologized only for 'having to reaccommodate ... customers'. A second statement called Dao 'disruptive and belligerent'. Finally, in a third statement, Munoz reversed course, decrying the situation and calling it a 'truly horrific event', and offered a direct apology to Dao. Munoz was scheduled to take on the role of Chairman at the company's 2018 annual stockholders' meeting. However, after the incident United said to believe 'that separating the roles of Chief Executive Officer and Chairman of the Board is the most appropriate structure at this time. Having an independent Chairman of the Board is a means to ensure that Mr. Munoz is able to more exclusively focus on his role as Chief Executive Officer.' United also announced a new 2017 compensation program for Munoz, along with that of other executives, that will be more closely tied to improved customer satisfaction.

The presence of the CEO within the organisation by walking around or, in larger organisations, by regular 'meet the president' events or through other means (e.g., video or other messages) must help to get the vision and mission engrained into the hearts and minds of everyone else within the organisation. All this, however, is about getting a message across, telling people what is wanted. The danger is that much of it all will come down to a conveying mode, delivering words of inspiration, explanation and unambiguous direction - 
not so much about receiving messages from 'down yonder' in the organisation.

Although this, of course, will not apply to your CEO, one employee in a large organisation shared with me the experience he had, having attended a 'meet the president' event for the first time: 'We all tried to look and behave at our best and tried to seize an opportunity to utter that one brilliant observation or question that would make you stand out and being remembered. That was not easy because most of the time the CEO himself was just broadcasting.'

A major challenge for a CEO is also to be authentically receptive for not so self-evident messages. His or her unique position creates a position of power with all the benefits but also the downsides thereof. It is not so easy to create a culture that avoids people conveying only the messages they think the CEO wants to hear and to refrain from expressing what they believe the CEO does not want to hear. The only one who can cause this dangerous situation to be different is the CEO him- or herself. It requires a climate for dialogue with the $\mathrm{CEO}$ and in the organisation as a whole, which invites, stimulates and allows asking probing and insightful questions both upstream and downstream.

In his book Theory in Practice (1974), the famed author on management Chris Argylis and his colleague Donald Schön show how people pay lip service to certain beliefs ('espoused theory') but act in a manner that deviates from what they espoused ('theory in practice'). In tensed situations - for example, when meeting with what resembles criticism - people will actually behave in a manner that is not in line with their intentions. Unconsciously they fall back on defence mechanisms, which may frustrate or delay an open dialogue. The desire to safe face, protect oneself or others, or maintain the status quo stand in the way of learning from experiences, often leading to a culture of resistance against change. This applies to the CEO as well, who is just another human being. It is one thing to convey that 'the door is always open' and 'people can say everything to me' and another to practice what you preach.

I believe in the axiom that the culture of an organisation is determined at the top. I also believe that culture is the key factor for the durability and success of an organisation. Apart in cases of very protected niches in the market for its products or services, the experience of customers and other stakeholders is determined by the culture of the organisation. The experience of the culture will decide where people want to (continue to) work and obtain their products or services.

Creating an atmosphere within an organisation of what has been referred to as 'psychological safety', to an overriding extent, will have to come from the CEO and senior management. Psychological safety means people will feel free to share the things that scare them without fear of recriminations and talk about what is messy or sad. It will also allow for constructive confrontation with colleagues who drive others crazy and being receptive in discussions with customers. To establish and live such a culture is easier said than done. I know too many examples of people who lost their job as a result of openly addressing problems in or doubts about their organisation. Rather than being recognised for their courage to speak up, they were seen as disloyal and ousted from the group. Leadership more than ever has become an activity of creating conditions for a safe, flexible and self-correcting organisation. The authentic approach towards openness and psychological safety is determining how open people will dare be and how much of what may otherwise remain unknown to the CEO may come to the surface. It is not always easy to consider a negative message a gift rather than a blame. Inviting everyone to be open and fearless in word is not the same as walking the talk.

The CEO has an elevated position, having the final say in all issues of existential relevance for the organisation. Wanting to be and remain in control in order to keep a grasp on things if not out of fear for professional liability claims, the CEO is keen to know what is going on within the organisation. This objective is best served in a culture where people will openly come forward with their concerns and ideas. Such a culture, as said, has to be initiated and be carried by the CEO from the top down. That requires a CEO who is open to corporate mediation stuff. What does that mean? For one thing, it is a CEO who is able to burst out of the bubble, in which he or she can easily find him- or herself to exist. He or she may be like the emperor without clothes because no one will confront him or her directly. At the same time, it is the role of the CEO's loyal support network to make sure that their boss is not exposed and that he or she can choose from a well-stocked wardrobe, tailor made to perfection, that will deliver sartorial elegance suitable for every occasion.

In order to be receptive to 'the good and the bad', the CEO need not undergo a complete metamorphosis, but might begin by asking him- or herself the following 10 questions. These are reprinted here with the special permission of the Harvard Business Reviem (HBR), taken from an article by Hal Gregersen in $H B R$ March-April 2017 (titled 'Bursting the CEO Bubble'). An answer to these questions may indicate to the CEO whether he or she has become insulated from crucial ideas and information in his or her everyday work, and whether he or she is in fact open to this mediation stuff:

1. How many barriers do people have to cross to talk directly with you?

2. How much of your typical workweek is spent outside your office or headquarters?

3. When was the last time you were dead wrong about something at work?

4. How quickly did you uncover your last mistake? How fast did you change course?

5. How often do people ask you uncomfortable questions at work? 
6. How often do you talk with people who make you feel uncomfortable? How much time did you spend in places that make you feel uncomfortable?

7. How many questions do you ask versus statements you make in typical conversations?

8. How often do you wait silently (3 seconds or more) for others to answer your questions?

9. How many times this week have you said 'I don't know' in response to a question?

10. When was the last time your provocative questions gave rise to a catalytic story - one that radically transformed some part of your organisation for the better?

Answering the 10 questions may be of help to re-align in the event the result of incidental training courses organised by the HR department (soft skills, giving feedback and the like) has been watered down by the demands of getting things done every day, fighting off crisis or being occupied with other pressing and absorbing issues. One might say that the issues touched upon by the 10 questions are not new; in many cases, they indeed may have been brought to mind ever by a course organised by the HR department. Yet, an organisational culture to reflect these skills and values is not so common.

What probably was not taught at all, is how to constructively prevent and solve conflicts. Together with more understanding of negotiation, a mediation training offers effective tools to achieve personal goals and advance the objectives of the organisation. In the interview with Rob Huijten of Bayer Vegetable Seeds in this Journal, a good example is mentioned of the added value of the use of mediation skills turning a potential loss into added value. Instead of losing long-standing customers, a new fruitful cooperation resulted from an approach focussed on joint interests rather than on who was right and who was wrong when something went amiss.

Recommended here is that a CEO take time off - which in itself will be quite a challenge - and enlist for a fullfledged mediation training. To become familiar with the philosophy of mediation and how it may influence the behaviour of counterparts will benefit not only the CEO but also the entire organisation. A CEO can thus become open to this corporate mediation stuff, and mediation may become corporate stuff. Mediation training entails more than learning to ask open questions or to give and receive feedback. It will help the CEO to experience during more days of consecutive training him- or herself the effect of deploying mediation techniques and what it does to counterparts. The effectiveness of the relevant techniques to prevent and solve conflicts alone will render an immediate payback on the investment in the mediation training. Learning to mirror and reframe, discovering underlying interests, knowing a safe way to ask questions, applying a safe reality test and knowing when to remain silent (among many more things) will provide the $\mathrm{CEO}$ with much added value. This applies both in cases of conflicts and in commercial dealings.
The relevance of the art of asking questions is confirmed in what I believe to be a very pointed quote from SAP's CEO Bill McDermott ('Bursting the CEO Bubble', $H B R$, March-April 2017). He pointed out that as managers get promoted up the ranks, they reach their limits fast if they aren't able to ask probing and insightful questions. 'At the top layers of the organisation, the people with the most potential to succeed', he says, 'are the ones who can "take difficult situation and bring it to its knees with questions". Like Bill McDermott whose company is one of the founding fathers of a group of companies in Germany with a vocation to stimulate mediation within and between organisations, the Round Table Mediation und Konfliktmanagement der Deutschen Wirtschaft - your CEO may come to appreciate the difference mediation skills can make in achieving his or her own personal objectives. In addition, the entire organisation will benefit by advancing the deployment of those skills at all levels and also between organisations, as said, also in commercial negotiations. Conflicts can be prevented or solved without escalating. The payback in this respect may be enormous. The importance of mediation skills with respect to risk management and compliance can hardly be exaggerated either. This is stressed by Professor D. Weiss, founding director of the Institute for Dispute Resolution (IDR) at New Jersey City University, in his contribution to this Journal. He recommends that mediation skills will be included in the curriculum of business schools. Similarly, Claire Mulder in her contribution emphasises the relevance of mediation skills to lawyers and legal professionals. She argues that training in mediation should become a core part of a legal studies degree.

Quite possibly, the CEO will also begin to appreciate the added value of creating a special space for institutionalised mediation in the organisation. Anna Doyle, internal mediator and ethics officer of Eurocontrol, explains in her contribution to this Journal the many advantages of doing so. To have an internal mediation service is one way of taking the pulse and temperature of what is going on under the radar from different perspectives - human, social, technical, political, economic and organisational. In the annual report of an internal mediator, the general nature of concerns that people have at work is observed and documented. Taking it one step further, it can also promote corporate awareness and an enlightened approach to informed decision making.

A CEO who is open to this corporate mediation stuff will soon experience the advantages of the culture it can breed. Hidden risks lurking inside the organisations may become known, and early warning signals may be delivered without fear for repercussion. The bottom line of this Editorial is that deploying mediation skills within and between organisations is the smartest way of getting things done better, more accepted and without much of the resistance, friction or conflicts that otherwise occur so often. 
A nuance is in place here because national cultures may make all the difference in the way people relate to each other within an organisation. There are so-called egalitarian cultures and hierarchical cultures. In egalitarian cultures (e.g., Denmark, The Netherlands, Israel, Sweden, Australia, Canada and Finland) the ideal distance between a boss and subordinates is low. The best boss is the facilitator among equals. Organisational structures are flat. Communication may skip hierarchical lines. In hierarchical cultures (e.g., France, Italy, Spain, Poland, Russia, China, Japan and Mexico) the ideal distance between a boss and a subordinate is high. The best boss is a strong director who leads from the front. Status is important. Organisational structures are multi-layered and fixed. Communication follows set hierarchical lines. Germany, the United Kingdom and the United States rank somewhere in between. ${ }^{1}$

The Corporate Mediation Fournal is the platform for the exchange of insights and experiences from and for readers in the expanding field of corporate mediation. 